Report No. BMI- 1297

UC - Metallurgy and Ceramics

(TID-4500, 14th Ed.)

Contract No. W-7405-eng-92

COATING OF URANIUM DIOXIDE POWDERS

by

Joseph H. Oxley

James $F$. Hannah

John M. Blocher, Jr.

Ivor $\mathrm{E}$. Campbell

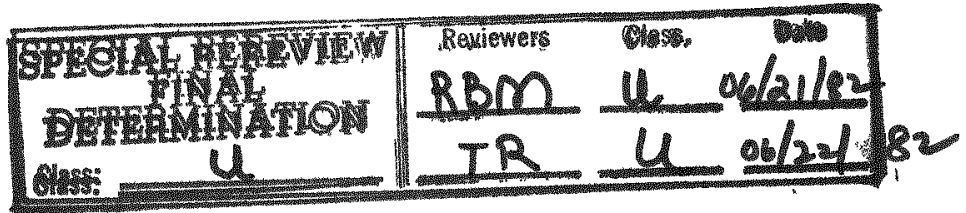

October 8, 1958

BATTELLE MEMORIAL INSTITUTE

$505 \mathrm{King}$ Avenue

Columbus 1, Ohio 


\section{DISCLAIMER}

This report was prepared as an account of work sponsored by an agency of the United States Government. Neither the United States Government nor any agency Thereof, nor any of their employees, makes any warranty, express or implied, or assumes any legal liability or responsibility for the accuracy, completeness, or usefulness of any information, apparatus, product, or process disclosed, or represents that its use would not infringe privately owned rights. Reference herein to any specific commercial product, process, or service by trade name, trademark, manufacturer, or otherwise does not necessarily constitute or imply its endorsement, recommendation, or favoring by the United States Government or any agency thereof. The views and opinions of authors expressed herein do not necessarily state or reflect those of the United States Government or any agency thereof. 


\section{DISCLAIMER}

Portions of this document may be illegible in electronic image products. Images are produced from the best available original document. 


\section{TABLE OF CONTENTS}

$\underline{\text { Page }}$

INTRODUCTION . . . . . . . . . . . . . . . . .

EXPERIMENTAL WORK . . . . . . . . . . . . . . . . . . 1

Description of the Equipment . . . . . . . . . . . . . 1

Experimental Procedure . . . . . . . . . . . . . . 4

Experimental Results . . . . . . . . . . . . . . . . 4

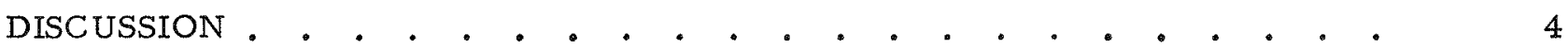

Process Operability . . . . . . . . . . . . . . . . . . . . . 4

Process Variables . . . . . . . . . . . . . . . 8

Product Quality . . . . . . . . . . . . . . . . . . . 9

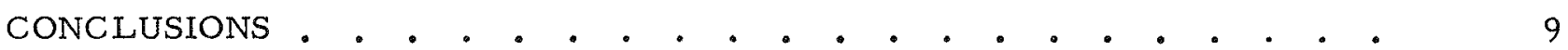




\title{
COATING OF URANIUM DIOXIDE POWDERS WITH METALLIC TUNGSTEN FILMS
}

\author{
Joseph H. Oxley, James F. Hannah, \\ John M. Blocher, Jr., and \\ Ivor E. Campbell
}

\begin{abstract}
Conditions for the tungsten coating of uranium dioxide powders by hydrogen reduction of tungsten hexachloride in a fluidized bed of the powder product have been established. The coated material should contain approximately 20 wo tungsten in order to obtain essentially complete coverage of micron-size uronium dioxide.
\end{abstract}

\section{INTRODUCTION}

Investigations of nuclear fuel elements capable of operating at high temperature have presented a number of problems which must be overcome if operating tempera-tures are to be increased. Problems which have become increasingly severe at higher temperature levels include loss of fission products, fusion of the fuel at the center of the element, volatilization of the fuel, and catastrophic failure of the fabricated element due to reduced strength, corrosion or exosion at elevated temperatures, and high power-generation rates.

Such problems have led to the development of multiphase fuel elements consisting of either metal and ceramic mixtures or mixtures of ceramic phases. A uniform dispersion involving a matrix material surrounding a uniformly distributed second phase is believed to be the optimum configuration for such elements. In addition, it is believed that if the dispersed phase material could be initially precoated with the matrix material, then this optimum configuration could probably be obtained by the use of such precoated material in the fabrication of the fuel element.

Recent studies at Battelle have shown that it is possible to obtain relatively uniform, adherent, and nonporous films on either ceramic or metallic powders by a modified vapor-deposition technique employing the powder to be coated as the bed in a fluidized-bed reactor. The following program was carried out as a result of interest in the tungsten-uranium dioxide system.

EXPERIMENTAL, WORK

Description of the Equipment

A schematic flow diagram of the apparatus used in this program is shown in Figure 1. Prepurified electrolytic hydrogen (Air Reduction Sales Company) was further purified by passing it through a Type 100-50 Deoxo catalytic burner (Baker and Company) and a Type BAC-25 Lectrodryer (McGraw-Edison Company) containing Molecular Sieve 


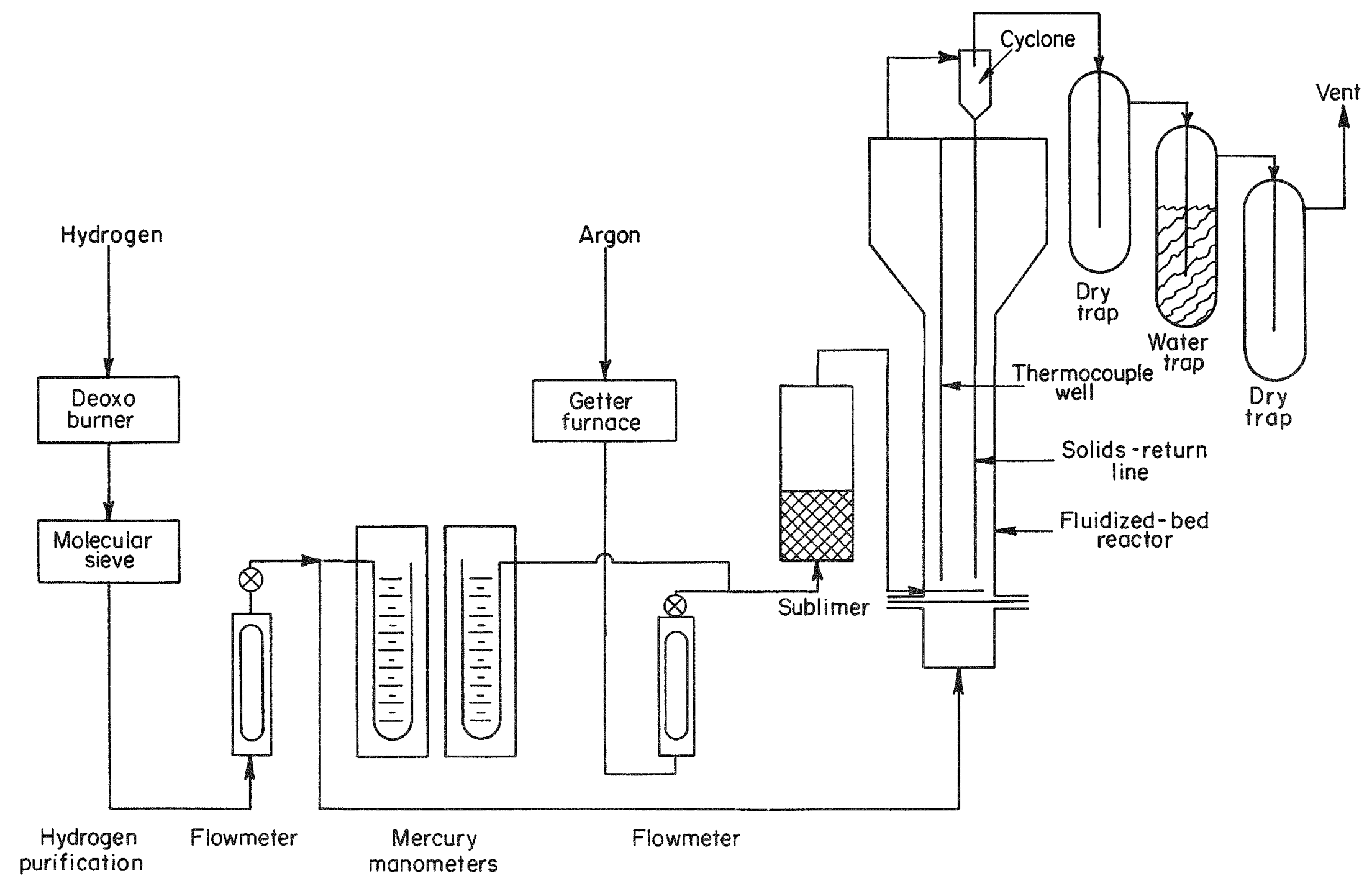

$N$

FIGURE 1. SCHEMATIC FLOW DIAGRAM FOR THE COATING PROCESS 
adsorbent. A Type 26-301 Moisture Monitor (Consolidated Electrodynamics Corporation) was used as a control for the dryer. A sample stream of the repurified hydrogen containing metered traces of argon (Linde Air Products Company) was continuously analyzed for detrimental impurities by means of a mass spectrometer during several of the experiments.

A zirconium getter furnace containing about $2 \mathrm{lb}$ of zirconium sponge was used for purification of the process argon. This furnace was constructed from a 2 -ft length of 1-1/2-in. stainless steel pipe.

The feed system for the tungsten hexachloride (A. D. MacKay, Inc.) consisted of a. stainless steel sublimation vessel with provision for introduction of argon carrier gas. The sublime $x$ was constructed from a 15-in. length of 1-1/2-in. stainless steel pipe. The chloride was charged to the sublimer through a screwed pipe cap fitting at the top of the vessel. The chloride in the sublimer was supported by a 400 -mesh stainless steel screen. Metered argon gas was passed up through this supported tungsten hexachloride bed which was maintained at a suitable temperature level by means of electrical resistance heaters mounted around the outside of the sublimer. The temperature of this vessel and the flow rate of argon were varied to obtain a given feed rate of tungsten hexachloride to the reactor.

The deposition reactor consisted of a 20-in. length of 1-1/2-in. stainless steel pipe. An expanded section of a 6 -in. length of 4-in. stainless steel pipe was mounted at the top of the reactor to minimize loss of the powder product by elutriation from the reactor. The uranium dioxide powder used in this program had an average particle size of about $1 \mu$. The bed of uranium dioxide was supported by a 400 -mesh stainless steel screen. This screen was held in position at the base of the fluidized-bed reactor by inserting it between a pair of slip-on flanges gasketed with stainless steel-clad asbestos rings.

The tungsten hexachloride inlet distributor was a length of 1/4-in. stainless steel tubing. The end of the inlet which projected approximately $1 \mathrm{in}$. into the fluidized bed was welded shut, and six holes 1/32 in. in diameter and six holes 1/16 in. in diameter were drilled in the sides of this inlet tube to assure uniform dispersion of the tungsten hexachloride vapors throughout the bed. This inlet was mounted approximately $1 / 2 \mathrm{in}$. above the support screen with its axis perpendicular to the axis of the reactor. Fluidizing and reductant hydrogen was introduced below the support screen for the powder bed. Heat for the reaction was transferred from external electrical-resistance heaters through the walls of the reactor. The reaction temperature was measured by means of a thermocouple in a stainless steel thermocouple well immersed directly in the bed.

Several devices were employed to add mechanical energy to the reactor as an aid in fluidizing the uranium dioxide. A University loudspeaker, SA-30, $30 \mathrm{w}$, was mounted several feet below the supporting screen for the fluidized bed and was coupled to the $r$ eactor by means of rubber radiator hose. Two mechanical vibrators, made by the Syntron Company, Models V-15 and V-30, 75 and $150 \mathrm{w}$, respectively, were individually employed during various experiments. The mechanical vibrator was mounted directly on the side of the reactor.

A 1/4-in. - ID cyclone was mounted on top of the expanded section of the reactor after Run 4. The solids-return leg of this cyclone extended back down into the fluidized bed and terminated approximately $1 / 2$ in, above the supporting screen for the fluidized 
bed. A dry solids trap, a water-washing solids trap, and a filter trap filled with glass wool were employed to prevent serious loss of the powder product from the reaction system.

\section{Experimental Procedure}

The procedure for the reduction runs was fairly standardized. The reactor was charged with several hundred grams of uranium dioxide. The sublimer was charged with approximately $100 \mathrm{~g}$ of tungsten hexachloride. The sublimer, reactor, and trap systems were then coupled and leak tested. The equipment was then purged with argon and brought up to the desired reaction temperature. The mechanical vibrator was then turned on, the hydrogen flow was increased to somewhat above the rate for incipient fluidization, and a metered argon flow passed through the sublimer and into the reactor.

After a given treatment time, varying from a few up to $12 \mathrm{hr}$, the argon flow through the sublimer was terminated and the reactor and sublimer cooled to room temperature and then purged with argon. The bed, sublimer, and material collected in the traps were weighed. The coated material was screened and analyzed for tungsten. In several cases, complete analyses for impurities in the deposited metal were also performed. The conversion and material balances for the runs were determined from these data.

Examination of the product for uniformity of coating was carried out by using a polarized light and an optical microscope. The uranium dioxide has a red color and tungsten has a green or silver color when examined under polarized light. This color contrast provided an excellent method of determining the uniformity of the coatings.

\section{Experimental Results}

A summary of the experimental data for the deposition experiments is presented in Table 1. Analytical data on the impurities in the products from several selected runs, as well as the analytical data on the feed materials, are given in Table 2. Black and white prints of color photomicrographs of the uncoated, partially coated, and completely coated uranium dioxide are shown in Figures 2, 3, and 4.

\section{DISCUSSION}

\section{$\underline{\text { Process Operability }}$}

Preliminary experiments in a small glass model of the deposition reactor indicated that the application of low-frequency mechanical vibration to the walls of the reactor was necessary for satisfactory fluidization of the uranium dioxide powder. The use of higher frequency sonic energy generated by a conventional speaker driver unit did not significantly improve the fluidizability of the very fine uranium dioxide powder. 
TABLE 1. SUMMARY OF EXPERIMENTAL DATA ON COATING OF URANIUM DIOXIDE POWDER BY HYDROGEN REDUCTION OF TUNGSTEN HEXACHLORIDE

\begin{tabular}{|c|c|c|c|c|c|c|c|c|c|c|c|c|c|c|c|c|c|c|c|c|c|}
\hline & \multicolumn{21}{|c|}{ Run } \\
\hline & 1 & 2 & 3 & 4 & 5 & 6 & 7 & 8 & 9 & 10 & 11 & 12 & 13 & 14 & 15 & 16 & 17 & 18 & 19 & 20 & 22 \\
\hline Bed Temperature, C & 550 & 450 & 500 & 550 & 550 & 450 & 450 & 450 & 550 & 550 & 550 & 550 & 550 & 550 & 550 & 530 & 450 & 400 & 400 & 400 & 400 \\
\hline Bed Source & $A R(a)$ & AR & AR & AR & AR & $\begin{array}{c}\text { Cyclone } \\
\text { Runs } 2 \\
\text { and } 4\end{array}$ & Run 6 & Run 7 & $\begin{array}{l}\text { Run } 5, \\
\text { Cyclone } \\
\text { Run } 3\end{array}$ & AR & AR & $\begin{array}{l}\text { Residues } \\
7,8,9,10\end{array}$ & AR & AR & AR & (b) & AR & AR & AR & AR & AR \\
\hline Run Time, min & 30 & 75 & 90 & 60 & 45 & 90 & 190 & 120 & 855 & 600 & 520 & 720 & 660 & 540 & 540 & 480 & 600 & 600 & 600 & 600 & 720 \\
\hline Hydrogen Rate, scfm & 0.26 & 0.26 & 0.26 & 0.26 & 0.26 & 0.26 & 0.26 & 0.26 & 0.26 & 0.26 & 0.26 & 0.19 & 0.19 & 0.19 & 0.19 & 0.24 & 0.19 & 0.24 & 0.24 & 0.24 & 0.24 \\
\hline Argon Rate, scfhr & 2.0 & 1.1 & 2.0 & 2.0 & 2.0 & 1.0 & 2.0 & 2.0 & 2.35 & 4.0 & 3.0 & 3.0 & 3.0 & 3.0 & 3.0 & 3.0 & 2.5 & 2.0 & 2.0 & 2.0 & 2.0 \\
\hline Excess Hydrogen Ratıo(c) & 66 & 165 & 298 & 139 & 124 & 480 & 152 & 325 & 300 & 151 & 135 & 158 & 96 & 74 & 105 & 290 & 86 & 107 & 196 & 143 & 114 \\
\hline \multirow{2}{*}{\multicolumn{22}{|c|}{$\begin{array}{l}\text { Vibrator Power, w } \\
60 \mathrm{cps}\end{array}$}} \\
\hline & 10 & 60 & 75 & 80 & 65 & 65 & 35 & 50 & 60 & 60 & 60 & 55 & 60 & 60 & 60 & 40 & 165 & 150 & 185 & 140 & 125 \\
\hline $400 \mathrm{cps}$ & 25 & 25 & 25 & 25 & 25 & 25 & 25 & 35 & 35 & - & - & - & 25 & 25 & 25 & 25 & - & - & - & - & - \\
\hline Intral Bed Weight, g & 225 & 237 & 239 & 234 & 283 & 259 & 250 & 171 & 279 & 420 & 420 & 471 & 420 & 420 & 420 & 420 & 450 & 450 & 450 & 450 & 450 \\
\hline Total Tungsten Deposted, g & 0 & 7 & 6 & 8 & 7 & 4 & 15 & 4 & 50 & 67 & 24 & 52 & 91 & 82 & 60 & 27 & 81 & 65 & 33 & 62 & 69 \\
\hline Total Feed Werght, $g$ & 225 & 244 & 245 & 242 & 290 & 263 & 265 & 175 & 329 & 487 & 444 & 523 & 511 & 502 & 480 & 447 & 531 & 515 & 483 & 512 & 519 \\
\hline Final Bed Weight, g & 217 & 120 & 120 & 81 & 228 & 222 & 200 & 132 & 208 & 194 & 137 & 313 & 318 & 294 & 239 & 158 & 413 & 225 & 225 & 333 & 102 \\
\hline Weight of Recovered Loss, g & 0 & 114 & 112 & 148 & 53 & 39 & 63 & 39 & 117 & 204 & 206 & 178 & 170 & 136 & 149 & 234 & 54 & 125 & 93 & 82 & 145 \\
\hline Weight Below Screen, g & - & - & - & - & - & - & - & - & - & - & - & - & - & - & - & - & - & 112 & 130 & 65 & 274 \\
\hline Total Product Weight, $\mathrm{g}$ & 217 & 234 & 232 & 229 & 281 & 261 & 263 & 171 & 325 & 398 & 343 & 491 & 488 & 420 & 388 & 392 & 467 & 462 & 449 & 480 & 521 \\
\hline Net Process Loss, g & 8 & 10 & 13 & 13 & 9 & 2 & 2 & 4 & 4 & 89.4 & 101 & 32 & 23 & 82 & 92 & 55 & 64 & 53 & 39 & 32 & $\cdot 2.3$ \\
\hline Relatıve Loss, per cent & 3.6 & 4.1 & 5.5 & 5.3 & 3.2 & 0.6 & 0.7 & 2.5 & 1.3 & 18.3 & $22.7(d)$ & 6.1 & 4.5 & 16.3 & 19.2 & 12.3 & 12.1 & 10.3 & 8.0 & 6.3 & -0.4 \\
\hline Weight Tungsten Feed, g & 9.3 & 9.3 & 6.5 & 8.8 & 7.4 & 3.7 & 25.5 & 6.5 & 57.5 & 80.4 & 64 & 64 & 101 & 107 & 75 & 30.6 & 103 & 94 & 57.6 & 78.5 & 117 \\
\hline Tungsten Converted, per cent & 0 & 75 & 98 & 90 & 97 & 100 & 58 & 68 & 88 & 84 & 37 & 82 & 90 & 78 & 80 & 88 & 79 & 69 & 64 & 80 & 58.5 \\
\hline \multicolumn{22}{|l|}{ Screen Analysis, per cent } \\
\hline Plus 100-Mesh Fina! Bed & - & - & $90(+325)$ & 5 & 5 & 5 & 5 & 15 & 10 & 25 & 13 & 18 & 10 & 27 & 31 & 25 & 4,4 & 0 & 0 & 0 & 0 \\
\hline Minus 100-Mesh Final Bed & - & - & $10(-325)$ & 95 & 95 & 95 & 95 & 85 & 90 & 75 & 87 & 82 & 90 & 73 & 69 & 75 & 95.6 & 100 & 100 & 100 & 100 \\
\hline \multicolumn{22}{|l|}{ Tungsten Analysis, per cent } \\
\hline Plus 100-Mesh Final Bed & $<0.006$ & $3.5-5 \%$ & $3.5(+325)$ & $20-30$ & 11.5 & 11.7 & 8.3 & 22.6 & 39.1 & 48 & 20.3 & 41.2 & 39.2 & 39.3 & 43.2 & 29.2 & 32.0 & - & - & - & - \\
\hline Minus 100-Mesh Final Bed & $<0.006$ & $3.5-5 \%$ & $2.6(-325)$ & 5.8 & 2.3 & 2.9 & 9.4 & 9.9 & 21.4 & 16.5 & 9.7 & 20.5 & 24.0 & 20.3 & 13.5 & 11.4 & 19.4 & 19.5 & 10.0 & 13.9 & 14.3 \\
\hline Recovered Loss & - & 1.5 & 2.0 & 1.6 & 1.7 & 1.6 & 4.9 & 9.9 & 6.9 & 9.7 & 4.2 & 9.5 & 6.4 & 5.0 & 4.2 & 7.8 & 4.8 & 8.8 & 7.0 & 8.5 & 8.0 \\
\hline Below Screen & - & - & - & - & - & - & - & - & - & - & - & - & - & - & - & - & - & 9.1 & 6.7 & 15.0 & 15.5 \\
\hline Deposition Rate, $\mathrm{lb} /(\mathrm{hr})\left(\mathrm{ft}{ }^{2}\right)$ & - & 1.03 & 0.74 & 1.45 & 1.68 & 0.454 & 0.865 & 0420 & 0.645 & 1.24 & 0.50 & 0.80 & 1.52 & 1.68 & 1.22 & 0.62 & 1.48 & 1.19 & 0.80 & 1.31 & 1.2 \\
\hline
\end{tabular}

(a) $\mathrm{AR}=\mathrm{UO}_{2}$ powder, as reduced

(b) Starting bed made up of odd lots of miscellaneous products.

(c) Ratio of hydrogen used to storchiometric equivalent.

(d) Losses due to cyclone breakage. 
TABLE 2. ANALYTICAL DATA ON FEED AND PRODUCT MATERIALS

\begin{tabular}{|c|c|c|c|c|c|c|c|c|}
\hline & \multicolumn{8}{|c|}{ Impurities, ppm by weight } \\
\hline & \multicolumn{2}{|c|}{ Feed } & \multicolumn{6}{|c|}{ Product Frnm Run Indicated } \\
\hline & $\mathrm{WCl}_{6}$ & $\mathrm{UO}_{2}$ & 4 & 5 & 8 & 9 & 18 & $18 \mathrm{~A}(\mathrm{a})$ \\
\hline$N$ & - & $<10$ & - & - & - & 110 & 10 & - \\
\hline C & - & 20 & - & - & - & 280 & 40 & - \\
\hline $\mathrm{Cl}$ & - & - & $<300$ & - & - & - & 5000 & 1900 \\
\hline $\mathrm{Fe}$ & $3-30$ & 300 & 300 & 1000 & 2000 & 4000 & 2000 & - \\
\hline $\mathrm{Cr}$ & - & 20 & 150 & 60 & 60 & 120 & 200 & - \\
\hline $\mathrm{Ni}$ & - & 15 & 100 & 100 & 120 & 130 & 20 & - \\
\hline $\mathrm{Si}$ & $5-50$ & 5 & 150 & 40 & $<20$ & $<20$ & 200 & - \\
\hline $\mathrm{Cu}$ & $2-20$ & 80 & 100 & 50 & 100 & 60 & 5 & - \\
\hline$M g$ & $1-10$ & 80 & 200 & 60 & 8 & 5 & 50 & - \\
\hline Al & - & 20 & 200 & - & - & - & 200 & - \\
\hline $\mathrm{Mn}$ & - & 4 & 200 & - & - & - & 50 & - \\
\hline $\mathrm{Sn}$ & - & $<2$ & 2 & 8 & 20 & 15 & - & - \\
\hline B & $3-30$ & 4 & - & 1 & 1 & 5 & - & - \\
\hline $\mathrm{Ca}$ & $1-10$ & 50 & - & 30 & $<20$ & $<20$ & 100 & - \\
\hline Mo & - & 60 & - & 60 & 140 & 220 & - & - \\
\hline$C_{0}$ & - & 15 & - & 6 & 8 & 10 & - & - \\
\hline $\mathrm{Pb}$ & - & 15 & - & 10 & 60 & 15 & - & - \\
\hline V & - & 2 & - & - & - & - & - & - \\
\hline $\mathrm{Zn}$ & - & 20 & - & 35 & 70 & 25 & - & - \\
\hline $\mathrm{Ti}$ & - & - & - & - & - & - & 80 & - \\
\hline $\mathrm{Cd}$ & - & - & - & 0.6 & $<0.5$ & $<0.5$ & - & - \\
\hline
\end{tabular}

(a) Product from Run 18 was fluidized in hydrogen at $450 \mathrm{C}$ for $4 \mathrm{hr}$ to reduce rhloride content. 


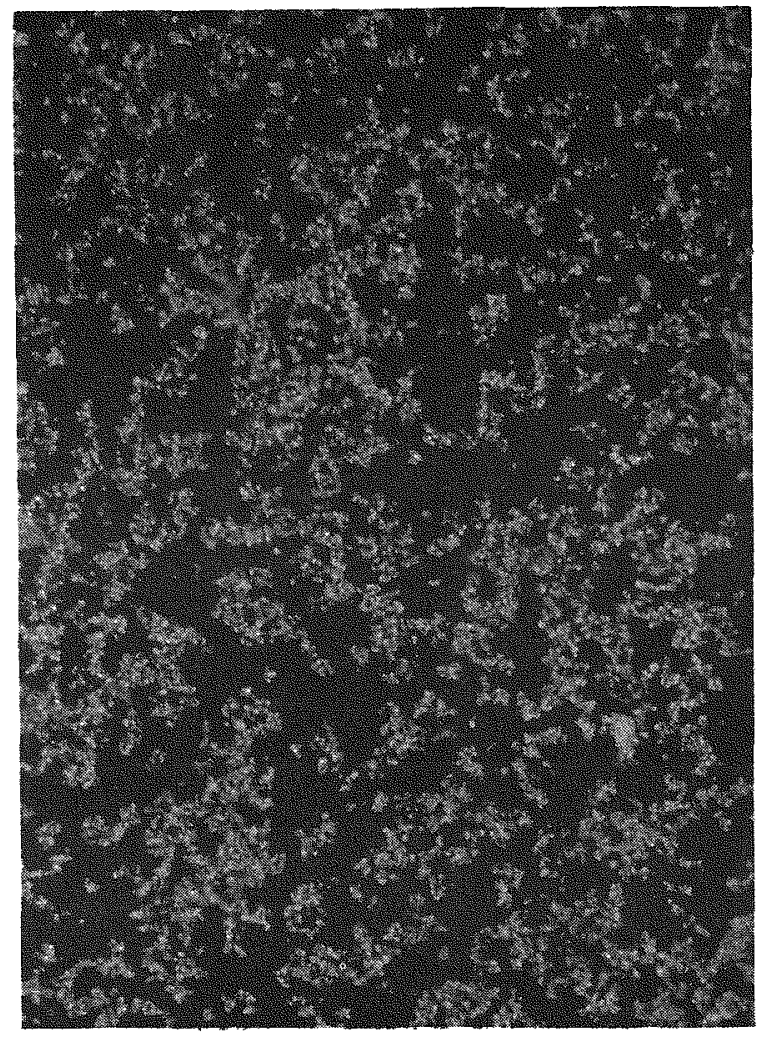

FIGURE 2. BLACK-AND-WHITE PRINT OF COLOR PHOTOMICROGRAPH OF UNCOATED URANIUM DIOXIDE STARTING MATERIAL

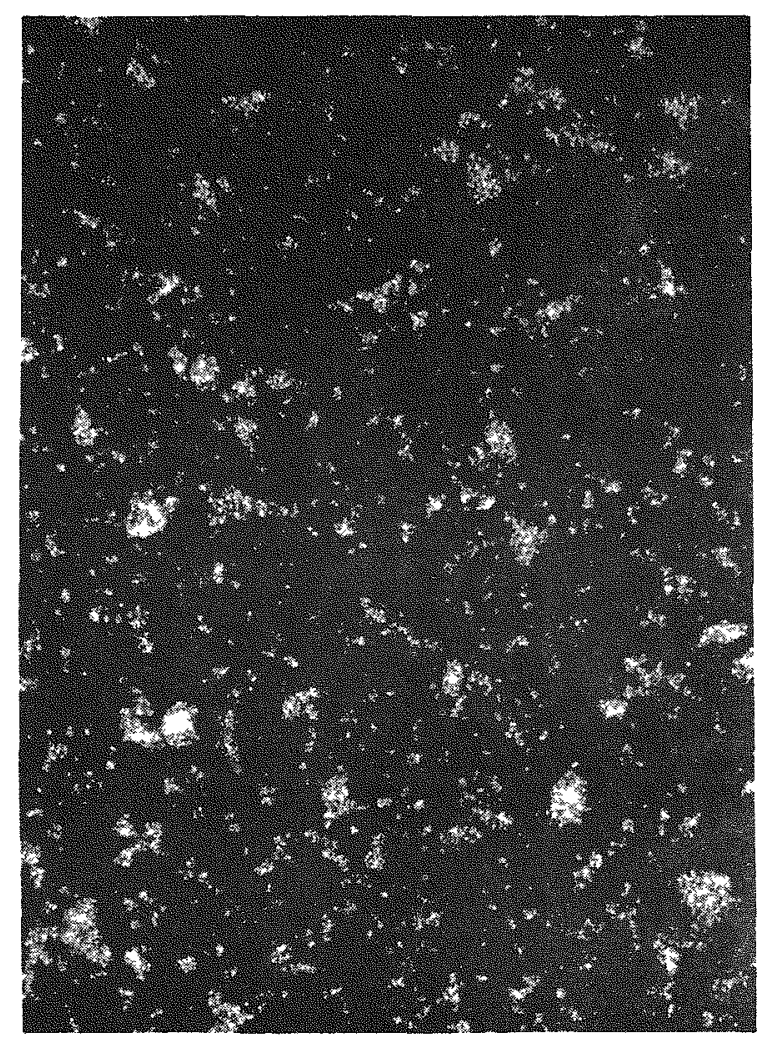

FIGURE 3. BLACK-AND-WHITE PRINT OF COLOR PHOTOMICROGRAPH OF PARTIALLY COATED PRODUCT FROM RUN 7

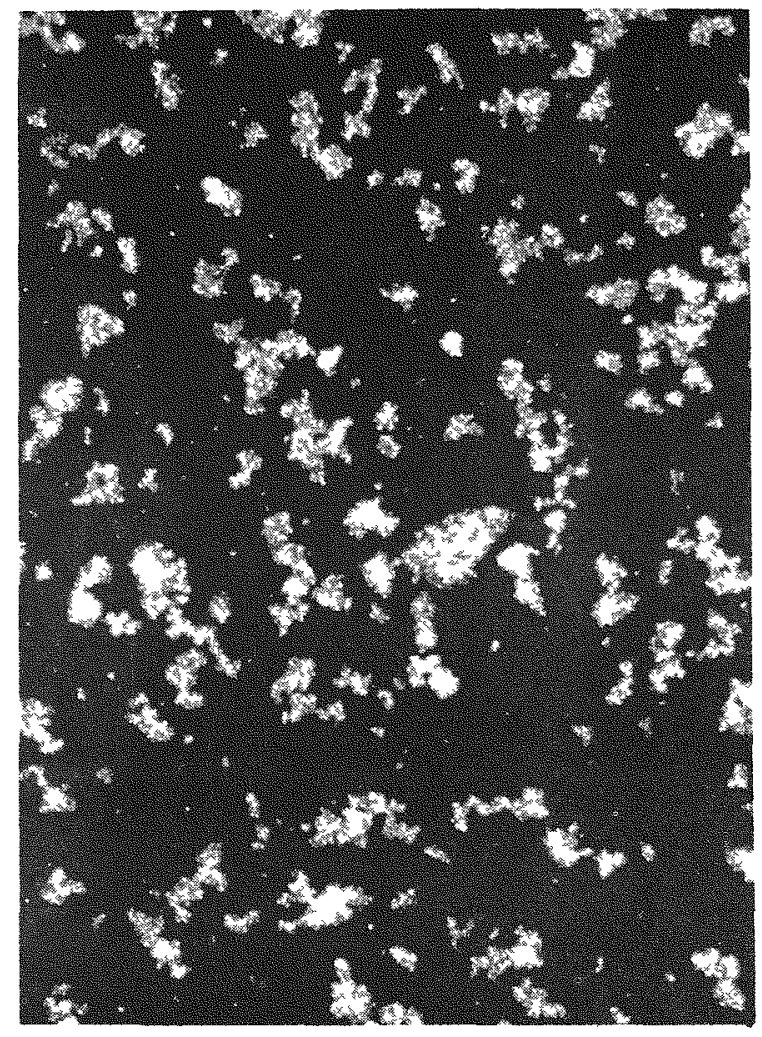

FIGURE 4. BLACK-AND-WHITE PRINT OF COLOR PHOTOMICROGRAPH OF COATED PRODUCT FROM RUN 18 
The use of sonic energy was therefore discontinued when it became apparent that the mechanically vibrated system permitted satisfactory operation of the reactor.

The importance of this mechanical vibration to the fluidized deposition process for coating very fine uranium dioxide powder cannot be overemphasized. The uniformity of fluidization is extremely poor when no mechanical vibration is employed. The dense uranium dioxide powder tends to pack into a claylike mass in the reactor and very little solids turnover occurs, even when relatively large amounts of hydrogen are passed through the bed. The hydrogen tends to channel through the packed uranium dioxide powder. However, by using sufficient mechanical vibration to collapse these channels, the bed takes on ebullient properties of the normal fluidized bed.

It also appears as if there is a certain threshold rate of energy addition for satisfactory operation of the particular system under study. Not only is the quality of gross fluidization rather poor at low levels of vibration but, in addition, the powder in the bed tends to segregate on the basis of different densities and particle sizes. If the rate of energy input to the reactor system used in the present investigation was somewhat less than $150 \mathrm{w}$, then the fraction of the powder which was initially coated segregated at the bottom of the bed and prevented the uncoated powder from contacting the tungsten hexachloride vapors. This segregation of the partially coated powder during the coating process resulted in a rather wide range of surface coverage for the individual particles from a given experiment. However, the use of energy-input rates of $150 \mathrm{w}$ or higher resulted in a relatively homogeneous product.

It was also demonstrated during these deposition studies that operation of the fluidized-bed reactor at a temperature level somewhat above $400 \mathrm{C}$ caused most of the powde $x$ which was coated to sinter and form agglomerates. Formation of these agglomerates resulted in an even more rapid and pronounced bed segregation than would normally be anticipated. Although this agglomeration difficulty was never completely eliminated, operation of the reactor at a temperature of about $400 \mathrm{C}$ and the use of relatively high levels of mechanical vibration yielded a satisfactory coating with respect to uniformity.

Employment of a system for disentrainment and recycling of solids was also essential for attractive yields of coated powder. Because the uranium dioxide powder consists of very small particles, and because this powder is very difficult to fluidize, there is a strong tendency for it to be elutriated from the reactor under conditions which permit a satisfactory degree of fluidization. The use of the small-diameter cyclone with a solids-return leg permitted return of this elutriated product to the reactor for further processing.

\section{Process Variables}

Considerable excesses of hydrogen are required for reduction of tungsten hexachloride to metal at a temperature of about $400 \mathrm{C}$. For convenience, the amount of hydrogen used in the various experiments has been expressed in terms of the excess hydrogen ratio, which is defined as the amount of hydrogen actually used divided by the stoichiometric amount for complete reduction of the tungsten hexachloride. Excess hydrogen ratios between 100 and 150 were found to be necessary for efficient conversions to deposited metal. 
Higher conversion of the tungsten hexachloride to tungsten could be obtained with higher bed temperatures, but the use of these higher temperatures resulted in the sintering problem previously discussed. At an excess hydrogen ratio of 150 , average conversions of 70,75 , and 90 per cent were obtained at bed temperatures of 400,500 , and $550 \mathrm{C}$, respectively. The use of higher excesses of hydrogen did not significantly increase these conversion levels. However, it is quite probable that reduction of the hexachloride in deeper beds would yield higher conversion levels at a given reaction temperature and excess hydrogen ratio.

Deposition rates from 0.4 to $1.7 \mathrm{lb}$ of tungsten per hour per square foot of reactor cross sectional area were obtained in these coating experiments. A deposition rate of $1.2 \mathrm{lb} /(\mathrm{hr})\left(\mathrm{ft}^{2}\right)$ appears to be a reasonable design estimate on the basis of all the reduction experiments carried out during this study.

\section{Product Quality}

The quality of the product with respect to purity of deposited metal is relatively good with the exception of iron and chlorine. All other impurities were below the $200 \mathrm{ppm}$ level for tungsten deposits of approximately $20 \mathrm{w} / \mathrm{o}$. The source of the iron contamination is, of course, due to corrosion of the reactor and sublimer. The product from Run 18 contained approximately $2000 \mathrm{ppm}$ iron. However, this level could be reduced by improved design of the equipment.

The chloride contamination was especially high in those products which were prepared at temperatures of about $400 \mathrm{C}$. The reduction reaction is the rmodynamically less favorable at low reaction temperatures and, in order to minimize the sintexing problem by operating at reduced temperature levels, special precautions must be taken to avoid traces of unreacted lower chlorides in the deposited metal. A postreduction hydrogen treatment of the product from Run 18 for $4 \mathrm{hr}$ at a temperature of $450 \mathrm{C}$ lowered the chloride content from 5000 to $2000 \mathrm{ppm}$. Further reductions in this chloride content could undoubtedly be obtained by more severe clean-up treatments. However, it is quite possible that this relatively high chloride content of the product could be avoided by the use of higher excess of hydrogen during the deposition process.

The quality of the product with respect to uniformity of coverage is excellent if the reduction is carried out at about $400 \mathrm{C}$ and if sufficient mechanical vibration is employed to assure good solids mixing in the fluidized bed. Approximately $20 \mathrm{w} / 0$ tungsten is required to achieve essentially complete coverage, although heavier deposits may be required to obtain the most satisfactory fabricated fuel element. Examination of the products which contained less extensive deposits always revealed incomplete surface coverage of the particles.

\section{CONCLUSIONS}

On the basis of the experimental evidence contained in this report, it may be concluded that: 
(1) Coating of uranium dioxide powder with metallic tungsten films by hydrogen reduction of tungsten hexachloride in a fluidized bed appears to be feasible at a reaction temperature of about $400 \mathrm{C}$.

(2) High conversions of tungsten hexachloride to deposited metal can be obtained at an excess hydrogen ratio of about 125 to 1 .

(3) Mechanical vibration of the reactor is essential for uniform and complete coverage of micron-size uranium dioxide powder.

(4) Deposits of approximately $20 \mathrm{w} / \mathrm{o}$ tungsten are required for es sentially complete coverage of the micron-size uranium dioxide powder.

(5) The purity of the deposited metal in the product from a production reactor would probably be dependent upon the purity of the tungsten hexachloride feed. 